\title{
Culpability and Compensation in Canadian Health Care: Much Ado About No-Fault?
}

\author{
Chris Hubbard*†, B.A., LL.B.
}

In 1990, J. Robert Prichard released his report (1) to the Conference of Deputy Ministers on "Liability and Compensation in Health Care." He concluded that from 1975 to 1990 there had been significant growth in the frequency and severity of malpractice claims, insurance premiums and the cost of malpractice litigation. Despite this growth, only about ten percent of persons suffering avoidable health care injuries with potentially viable claims received compensation. Prichard also concluded that there was enormous opportunity for further growth in malpractice litigation, and no reason to believe that this growth would not occur over the next decade or two. Nevertheless, he could not conclude that his findings were indicative of a malpractice "crisis". Rather, he surmised that the problem was "...confined to a serious situation that imposes significant costs, pressure and anxieties, and leaves a very large number of injured but uncompensated people" (1).

In 1996, the Canadian Medical Protective Association (CMPA) released its annual report "A Year Under Scrutiny." In the President's Preface, W.D.S. Thomas commented:

\begin{abstract}
The year 1996 was a difficult one for the CMPA. At a time when awards and settlements for medical malpractice are reaching new highs and the cost of legal liability coverage for doctors is escalating at an alarming rate, it is not difficult to understand why the methods of calculating the funds needed to provide such coverage are being challenged (2).
\end{abstract}

The total disbursements paid by the CMPA increased from approximately $\$ 71$ million in 1980 to $\$ 146$ million

\footnotetext{
* To whom correspondence should be addressed: RR\#3, Orangeville, ON, L9W 2Z1. E-mail: cmhubbar@julian.uwo.ca.

$\dagger$ Faculty of Law, University of Western Ontario, London, Ontario.
}

in 1995 and \$188 million in 1996. While there were also increases in legal costs, expert honoraria and administrative expenses during this period, the major factor in this increase was damages - the money paid out for settlements or as a result of judgements in favour of plaintiffs at trial. This increase in awards and settlements was primarily due to an increase in the number of cases settled and in the mean cost of awards and settlements (2).

This phenomenon is not limited to Canada. Almost all western countries have experienced increases in damages for iatrogenic injuries as well as significant growth in malpractice litigation rates and premiums since the early 1970s. Consequently, this malpractice "problem" has received a great deal of attention in medical and legal literature. While Prichard may still be reluctant to refer to this phenomenon as a "crisis", the statistical and anecdotal evidence supports the assertion that there is a significant problem facing health care in the western world (3). Whether or not a malpractice crisis exists, the perception among physicians is that it does, and the effects of this perception are arguably just as destructive. Here, I examine these deleterious effects, the capacity of the Canadian tort system to deal with them, the nature of iatrogenic injuries, and the viability of a no-fault system of compensation for those injuries in Canada.

\section{THE EFFECTS OF THE MALPRACTICE PROBLEM}

Perhaps the most cited consequence of the malpractice "crisis", either actual or perceived, is defensive medicine. Defensive medicine refers to any change in the way a physician practises medicine in response to the threat of litigation. Both statistical and anecdotal evidence suggests that physicians' attitudes and conduct are noticeably affected by this threat $(4,5)$. 
However, this does not entail that all forms of defensive medicine adversely affect the delivery of health care. For example, a physician may take more time to explain risks or keep more accurate records in order to protect him/herself from litigious patients. Nevertheless, by definition, practising defensive medicine results in the physician's judgment being influenced by legal instead of clinical considerations. Thus, the threat of litigation also translates into an increased use of diagnostic services with questionable utility, needless procedures, unnecessarily long hospital stays and the withdrawal of some specialty services with particularly high risks $(6,7)$. While evidence of the effect of the threat of litigation on medical practice is predominantly American, preliminary Canadian studies suggest that it is possible to extrapolate to the Canadian context. As a result, it appears that the already taxed Canadian health care system is forced to bear the added expense of defensive medicine, despite diminished availability and quality of certain health care services.

\section{THE ABILITY OF THE TORT SYSTEM TO DEAL WITH MALPRACTICE}

Clearly the problem of medical negligence cannot be ignored. The prevalence of medical malpractice has been the subject of some debate. However, it certainly exists to some extent, and it is in the public's best interest to ensure that steps are taken both to abate its occurrence and to adequately compensate its victims (6). Indeed, these are the two fundamental objectives of tort law as it pertains to medicine: to provide compensation for the victims of medical injury and to deter negligent medical practice (8). While these objectives are commendable, the question remains as to whether the common law negligence system is an equitable and efficient deterrent that is capable of adequately compensating victims of iatrogenic injury.

Clearly the tort system affects medical practice. The problem, however, is that it does so indiscriminately. The severity of a patient's disability is the only significant predictor of tort damage awards for medical malpractice; there is no correlation with the occurrence of an adverse event due to negligence or to an adverse event of any type $(9,10)$. Consequently, physicians are driven from high-risk practice areas such as obstetrics and orthopaedic surgery, and the cost of malpractice insurance is driven to nearly prohibitive levels $(1,11)$. Defensive medicine is the natural consequence of this lack of specificity in the tort system, and the problem is compounded by the fact that bad doctors are less sensitive to the threat of castigation while good doctors are overly concerned about it (12). Although unjust, this psychology is understandable. While bad doctors are spared the brunt of malpractice costs because of insurance, all doctors who choose to defend against malpractice claims must expend considerable time and money, and reputations suffer regardless of outcome. Tort law's deterrent effect is overly broad. As such, it is neither equitable nor efficient $(3,13)$.

Similarly, the civil tort system fails to achieve its second objective, that of compensating the victims of medical misadventure (3). Despite the increasing cost of professional indemnity and insurance, there is a relatively low rate of recovery for those who suffer negligent injury - only about ten percent receive compensation (1). In effect, the tort system functions by under-compensating many and overcompensating a few, and a large portion of the total amount expended on the claims process never reaches the victims of medical injury because of administrative costs (10).

The reason the civil system has failed to achieve these dual objectives of compensating iatrogenic injury and deterring tortious medical practice is that it has failed to properly understand the necessity of medical fallibility. Consequently, the relationship between culpability, injury and compensation has been obscured.

\section{THE NATURE OF MEDICAL FALLIBILITY}

Medicine is necessarily fallible (14). Science is the search for knowledge; scientific progress is the overcoming of ignorance. As a result, science operates only where there is at least partial ignorance, and it is this ignorance which potentiates error. Thus, because medicine is a practice based on science, unintentional medical error may occur either as a result of the present limitations of medical science or from the negligence of the physician. If a physician performs a medical procedure that results in harm to the patient, then either the medical science in support of that procedure is to blame, or the physician, by not acting in accordance with the best knowledge available, was negligent. But unintentional medical error can also occur in a third way. While medical science is concerned with generalizations, medical practice must treat particular individuals. In practice, medicine is always an experiment to determine whether a specific treatment will work for a particular patient in unique circumstances. Thus, as it pertains to particular patients, medicine is necessarily fallible (14).

It follows that medical injury is not necessarily related to medical culpability (14). Iatrogenic injury may also occur because of the present limitations of medical science (ignorance) or its inherent fallibility; injury does not necessarily presuppose culpability. Conversely, negligent and culpable medical practice may exist in the absence of injury. As a result, professional discipline may be justified in the absence of injury. The tort system has failed to realize its objectives of compensating victims and deterring medical misconduct primarily because it has failed to appreciate that the nature of medicine itself 
requires the bifurcation of those concepts of culpability and injury. The tort system's ability to compensate victims of medical mishap is misguided by its insistence on fault. In theory, because a physician faced with a negligence suit is held to the standard of care of a reasonable professional in the same circumstances, the tort system's deterrent effect should be suitable. However, unless this standard is augmented by an informed understanding of the nature of medical fallibility, in practice, it will inevitably be inappropriate. While the civil system may be adequately equipped to adjudicate other instances of negligence, it is wholly inappropriate in the realm of medical mishap. The objectives of the tort system as it pertains to medical injury are only incidentally related. Therefore, one need not pursue them in tandem. Indeed, in both New Zealand and in Sweden they are not. Rather, in these two countries, the concepts of compensation and culpability are bifurcated, and nofault systems of compensation for iatrogenic injuries exist as alternatives to common law negligence.

\section{THE NO-FAULT ALTERNATIVE: PRACTICAL PROBLEMS WITH IMPLEMENTATION}

No-fault compensation for iatrogenic injuries is a viable alternative to the tort system. The no-fault schemes in New Zealand and Sweden have persisted for almost twenty-five years. From a theoretical standpoint, compensation sans fault is also more consistent with the nature of medical fallibility. However, no-fault is no panacea. This is evident from the fact that the no-fault schemes in both New Zealand and Sweden must continually adapt and reform in response to at least three practical problems with their implementation and administration.

\section{The Scope of Coverage}

The first problem with no-fault schemes concerns the difficulty of defining the scope of coverage. This involves devising an appropriate trigger mechanism for compensation and determining what compensation will include. The test for compensation is medical causation rather than negligence. However, a broad range of possible injuries can be causally connected with medical intervention. Thus, the exact parameters of the scheme must be precisely articulated if it is to be at all efficacious. Even then, in some circumstances it is essentially impossible to distinguish between the effects of a medical intervention and those of the underlying condition. Unfortunately, any legislative initiative must contend with problems of this type. All that can be done is to set parameters as precisely as possible, and deal with penumbral cases as they arise.

The system in New Zealand utilizes a "pigeon-holed" approach. The scope of coverage is defined, the type of compensation is predetermined, and compensation is triggered if the injury and circumstances can be subsumed within the prescribed definitions (3). On the other hand, in the Swedish system the trigger for compensation is procedural. An application for compensation and a written report by the treating physician must be submitted for review. Eligible claims are then forwarded to specialists for a final determination. If medical management caused the adverse event, the treatment was not appropriate or acceptable according to a medical standard and the injury was avoidable, the claimant will qualify for compensation. Like the system in New Zealand, the type of compensation is predetermined $(15,16)$.

The system in New Zealand works relatively well. However, given that penumbral cases will inevitably arise in determinations of eligibility and coverage, the procedural trigger mechanism employed in Sweden seems preferable. This procedural trigger permits greater flexibility than the more rigid pigeon-holed approach. Nevertheless, the three criteria employed by the Swedish system require examination.

The first criterion, that medical management caused the adverse event, is both appropriate and necessary in any no-fault scheme for iatrogenic injury. Eligibility for compensation should be contingent upon proof of medical causation rather than negligence: the patient should have to establish, as a prima facie case, that $\mathrm{s} / \mathrm{he}$ suffered a loss as a result of a medical intervention rather than a medical condition. However, the burden of proof on the injured patient should not be overly onerous. There must be a willingness to decide in favour of the patient where his/her case is presumptively plausible; it must be persuasive, but not necessarily conclusive. This is the only way to avoid the practical problem of distinguishing between the effects of medical interventions and those of the underlying condition while at the same time providing a meaningful and comprehensive system of compensation.

Considering the nature of medical fallibility, the second Swedish criterion, that treatment be unacceptable or inappropriate according to a medical standard, is problematic. Medicine is necessarily fallible, and that fallibility has three sources: negligent medical treatment, the present limitations of medical science and the inherent difficulties of extrapolating from general medical knowledge to treat specific individuals. Negligent medical treatment is, by definition, unacceptable and inappropriate according to a medical standard. However, the other two sources of fallibility assume compliance with current medical custom. Some "acceptable" and "appropriate" medical treatments will inevitably have deleterious effects. A scheme that limits coverage to injuries caused by negligent medical practice must make determinations of fault. For example, the New Zealand scheme limits the 
scope of coverage by defining medical misadventure as personal injury resulting from "medical error" or "medical mishap." To identify medical error, a physician's conduct is held to a standard of care reasonably to be expected in the circumstances. Consequently, schemes which make determinations of fault not only fail to remedy the problems associated with the present tort system, they possess them. The scope of coverage must extend beyond negligent medical conduct and accept the inherent limitations of medical science and practice. Fault is an inappropriate precondition for compensation.

Similarly, it is apparent that limiting compensation to avoidable injuries as the Swedish system does would seriously narrow the scope of the scheme. Again, compensation would be limited to patients injured by physicians who fail to act in accordance with the best medical knowledge available. Given the nature of medical fallibility, all other iatrogenic injuries are not avoidable in any practical sense. Thus, injuries should be indemnified if they meet the first criterion of the Swedish system. A no-fault compensation scheme should ask: "Did medical management cause the adverse event?" However, it should not be concerned with whether "treatment was appropriate or acceptable according to a medical standard" or with whether "the injury was avoidable." Nevertheless, while a determination of whether the intervention was appropriate or acceptable is itself an inappropriate criterion for compensation, it is a determination that must be made if the second major difficulty with nofault schemes is to be ameliorated.

\section{The Perception of Justice and Deterring Medical Misconduct}

Ironically, the second major problem with no-fault compensation is engendered by what is arguably its greatest asset. No-fault compensation is effective because it recognizes the nature of medical fallibility and consequently distinguishes between culpability, injury and compensation. It is concerned with compensating victims rather than determining culpability. However, while there is debate about the extent to which it occurs, negligent medical practice does exist. Because of the emphasis placed on compensation by no-fault schemes, they are not well suited to discourage or discipline medical misconduct. To state it categorically is perhaps unjustified, but it appears that in practice a dichotomy exists: one scheme cannot be both a comprehensive method of compensation for medical injury and an effective and equitable deterrent and disciplinary scheme for medical misconduct. No-fault compensation must be accompanied by some other means of supervising professional standards and determining whether a medical intervention was "appropriate or acceptable according to a medical standard."

Self-regulation is one option. How can judges, lawyers or laypersons with no medical education or experience be expected to evaluate the conduct of a specific physician in unique circumstances? Medical science has advanced at such a rapid pace over the last twenty-five years that even within the medical profession a physician of one specialty may not be competent to judge the standard of care of another specialty. Nevertheless, the problem with selfregulation is that doctors are notoriously poor at managing their problem colleagues (12). This too is due to the necessity of medical fallibility.

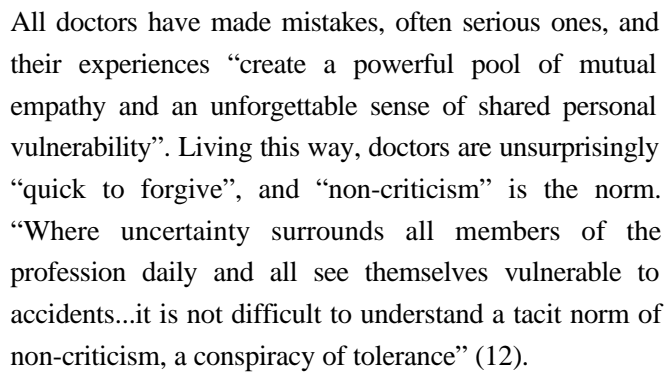

Thus, while self-regulation may be the only appropriate means of supervising professional medical conduct, it must be guided by predetermined external objective criteria if it is to overcome this natural tendency toward a "conspiracy of tolerance." For example, the "rarity" criterion employed by the New Zealand scheme is an equitable and efficient means of identifying problem doctors and practices. While negligent medical conduct may exist in the absence of injury, where an unexpected or rare injury results from a medical treatment, the treating physician's conduct warrants scrutiny.

The Prichard Report recommended that a no-fault compensation scheme be implemented as an alternative to tort action (1). However, tort claims should be restricted to cases in which the claimant is injured because the physician, by not acting in accordance with well established custom, is clearly and flagrantly negligent. Cases should only be referred to the tort system in extreme situations where punitive damages are potentially appropriate. Because this determination would only be made in rare cases by health care professionals guided by predetermined criteria, the deterrent effect should not be overly broad.

Sanctions and discipline are also necessitated by a desire for a "just" result. There is an intuitive justice inherent in the tort system: where a defendant is at fault, that defendant owes a debt to the injured plaintiff; the tort system ensures that it is paid. In a survey of individuals involved in no-fault programs for birthrelated neurological injuries in Florida and Virginia, 
claimants who received compensation were reasonably satisfied with all aspects of the no-fault system except the treatment of those responsible (17). Corrective justice fulfils a psychological need. However, compensation and justice are not the same thing. Justice requires that compensation somehow be connected with, and derived from, the cause of the injury; the guilty party must be held responsible. Due to the nature of medical fallibility, this justice is only appropriate where a physician, by not acting in accordance with the best medical knowledge available, is truly negligent. Nonetheless, it must be kept in mind that negligence can, and will, occur in the absence of injury. The implications of the nature of medical fallibility cut both ways. Where there is an injured patient, that patient must be involved in the disciplinary process. The patient must be aware that the physician has been held accountable for his/her misconduct.

This desire for justice must also be addressed where a patient's injury is the result of medical fallibility and not the negligence of a physician. This can only be achieved if physicians communicate effectively with their patients on an ongoing basis beginning at the earliest stages of their relationship. Patients must be aware of the inherent limitations of medicine. They must understand that physicians, medical science and medical practice are imperfect. Thus, physicians must discuss with patients, in accessible and frank words, the nature and potential outcomes of medical treatments and procedures, as well as possible alternatives. In the Birth Injury Survey, a desire to find out what went wrong was cited as a significant motive among both nofault and tort claimants for initiating claims (17). It is only if patients understand the nature and limitations of medicine that they will also understand that discipline is inappropriate in the absence of true negligence.

\section{Cost}

The third and most substantial impediment to the introduction of no-fault compensation is cost. Again, this problem is an inevitable consequence of the nature of no-fault schemes. It is difficult to devise an equitable means of funding no-fault schemes primarily because they aspire to comprehensively compensate victims of iatrogenic injuries without determinations of fault. While the extent of this problem will vary according to the scope of coverage, it will persist even where the scheme is very limited. This is because there is a substantial psychological component to this apparently economic criticism: where there are victims, there is also an inclination to find fault. However, it has been shown that, owing to the nature of medical fallibility, this inclination is often inappropriate in the realm of medical mishap. The paradigm shifts once it is accepted that injury is a natural, indeed an inevitable, consequence of medical practice. The impetus for nofault compensation should be community responsibility; its justification should be akin to that of publicly funded health care. No-fault compensation is a social welfare program. Nevertheless, this does not entail that no-fault schemes are economically inferior to the tort system, and there is evidence to suggest that nofault is more cost effective and efficient (16). For example, the Prichard report estimated that when

\footnotetext{
...account is taken of all the legal fees, the costs of the tort system, and the time and energy of everyone concerned with the litigation, in excess of 50 percent of all the money spent on malpractice goes to the expenses of litigation and not to the injured patient for the purposes of compensation (1).
}

On the other hand, it is estimated that the Swedish system's administrative costs account for approximately eighteen percent of its total budget (16).

Similarly, it becomes evident that punitive damages are inappropriate except in extreme cases of negligence. As a result, the scope of compensation, and therefore the overall expenditure, can be limited to tangible financial costs such as lost earnings, the cost of vocational rehabilitation and of medical treatment. Moreover, because no-fault compensation is a form of social welfare, in order to avoid duplication it should be offset by collateral benefits such as Workers' Compensation and Employment Insurance. It is difficult to predict with any degree of accuracy what the net cost of implementing and administering a system of no-fault compensation would be. However, in Canada, because the taxpayer bears the burden of health care, that cost would also be offset by the savings experienced as a result of the anticipated decline in defensive medicine resulting from the no-fault scheme. Furthermore, any monetary sanctions imposed on sub-standard doctors, and part of the moneys previously expended by physicians and hospitals on indemnity insurance premiums, could be redistributed to further subsidize the compensation program.

\section{BEYOND THE BOTTOM LINE}

Regardless of the "bottom line," the final analysis must consider more than economic factors. The Prichard Report recommends that any proposal for reform of liability and compensation issues in health care be evaluated against four normative benchmarks, three of which are not primarily economic considerations: "...reducing the frequency of avoidable medical injuries; enhancing social justice; and ensuring fairness among patients, health care professionals and health care institutions" (1).

The theory of medical fallibility that underlies no-fault compensation will inevitably foster a more realistic 
conception of what injuries are "avoidable." However, implementing a no-fault scheme will have limited impact on the actual frequency of avoidable medical injuries. Whether the number of avoidable medical injuries will decrease with the implementation of nofault compensation will depend on the effectiveness of the system of supervising medical standards and discipline that accompanies such a scheme. The tort system's experience with respect to medical misconduct is limited to cases that result in adverse events; its role is remedial. Given its specific expertise, a system of selfregulation is better equipped to identify negligent treatment before it results in injury. Such a system can impose the threat of sanction to deter medical misconduct, but it can also intervene to prevent it.

But it is no-fault's ability to enhance social justice and to ensure fairness among patients and health care providers alike that is its greatest asset. Patients benefit from more comprehensive, equitable, efficient and timely compensation without the stress of litigation; and the quality of health care and of the doctor/patient relationship is no longer diminished by defensive medicine. Physicians also benefit, both from the amelioration of the effects of the malpractice "crisis," and from the more appropriate and realistic expectations placed upon them by the legal system and by their patients.

The no-fault alternative strikes an attractive balance between Prichard's "benchmarks," and between normative and economic considerations. It is a comprehensive, efficient and equitable method of compensating medical injury and ensuring professional standards. Consequently, it is a viable proposal for reform of liability and compensation issues in Canadian health care.

A universal system of no-fault compensation for iatrogenic injuries would not be possible in every country. The environment in some Western economies, for example, would possibly be less receptive to such a scheme due to the commodification of health care and the consumerization of patients. However, the climate differs in Canada. Canadians pride themselves on their sense of social responsibility, and the existence of a publicly funded health care system suggests that this sense of obligation extends to the provision of health care. Often this sentiment is given legislative voice at the expense of individual autonomy. As a form of social welfare, no- fault compensation is no different. Individual liberties, such as the right to litigate and the right to spend tax dollars in alternate ways, must be sacrificed to effect such a scheme. However, if the choice is made, the benefits are great, and the benefactors are also the beneficiaries.

\section{REFERENCES}

1. Prichard JRS. Liability and Compensation in Health Care: A Report to the Conference of Deputy Ministers of Health of the Federal/Provincial/Territorial Review on Liability and Compensation Issues in Health Care. Toronto: University of Toronto Press; 1990.

2. Thomas WDS. "Preface" in A Year Under Scrutiny: Annual Report for the Year 1996. The Canadian Medical Protective Association; 1996.

3. Krever H. Commission of Inquiry on the Blood System in Canada. Ottawa: Minister of Public Works and Government Services Canada; 1997.

4. Kessler DP, McClellan MB. The effects of malpractice pressure and liability reform on physician's perceptions of medical care. Law and Contemporary Problems 60: 81-106; 1997.

5. Lawthers AG, Localio AR, Laird NM. Physicians' perceptions of the risk of being sued. Journal of Health, Politics, Policy and Law 17: 463-482; 1992.

6. Relman AS. Changing the malpractice liability system. New England Journal of Medicine 322: 626-627; 1990.

7. Hawkins C. Mishap or Malpractice. Oxford: Blackwell Scientific Publications; 1985.

8. Kinney ED. Malpractice reform in the 1990s: past disappointments, future success? Journal of Health, Politics, Policy and Law 20: 99-135; 1995.

9. Brennan TA, Sox CM, Burstin HR. Relation between negligent adverse events and the outcomes of medical malpractice litigation. New England Journal of Medicine 335: 1963-1967; 1996.

10. Dubin C. An Independent Review of the CMPA. 1997.

11. Johnson WG, Brennan TA, Newhouse JP, et al. The economic consequences of medical injuries. Implications for a no-fault insurance plan. JAMA 267: 2487-2492; 1992.

12. Smith R. All doctors are problem doctors. British Medical Journal 314: 841-842; 1997.

13. Bovberj RR. Medical Malpractice: Problems and Reforms. A Policy Maker's Guide to Issues and Information. Washington: The Urban Institute; 1995.

14. Gorovitz S, MacIntyre A. Toward a theory of medical fallibility. Hastings Center Report 5: 13-23; 1975.

15. Manuel BM. Professional liability: a no-fault solution. New England Journal of Medicine 322: 627-631; 1990.

16. Studdert DM, Thomas EJ, Zbar BI. Can the United States afford a "no-fault" system of compensation for medical injury? Law and Contemporary Problems 60: 1-34; 1997.

17. Sloan FA, Whetten-Goldstein K, Entman SS, et al. The road from medical injury to claims resolution: how no-fault and tort differ. Law and Contemporary Problems 60: 35-70; 1997.

Chris Hubbard received an Honours B.A. from the University of Toronto in Philosophy, specializing in biomedical ethics. He completed his LL.B. from the University of Western Ontario, London, Ontario in April, 2000. 